\title{
Research on the Relationship between Transportation Industry and Economic Growth
}

\author{
Jiaxin $\mathrm{Wu}^{1, \mathrm{a}^{*}}$, Yi Peng ${ }^{2, \mathrm{~b}}$, Xubing Zhou ${ }^{3, \mathrm{c}}$ \\ ${ }^{1}$ School of Economics and Management, Beijing Jiaotong University, Beijing, China \\ ${ }^{2}$ School of Economics and Management, Beijing Jiaotong University, Beijing, China \\ ${ }^{3}$ School of Economics and Management, Beijing Jiaotong University, Beijing, China
}

\begin{abstract}
Transportation industry is the leading capital of social and economic development, which plays an important role in regional economic development. Based on the data of Tibet Autonomous Region in the past 15 years, this paper makes further grey relation analysis and elastic analysis on the basis of analyzing the current situation of its transportation industry and economic development, obtains the conclusion about the development relationship between them. The empirical results show that there is a close relationship between the transportation industry and economic growth in Tibet Autonomous Region, and the development of them is in a state of coordination on the whole. Among them, the promotion effect of freight transport on the economic growth of Tibet is greater than that of passenger transport, and the belt action of economic growth on railway transport is much greater than that on highway transport.
\end{abstract}

\section{Introduction}

As a basic industry to promote economic development, transportation industry plays an increasingly significant role in promoting regional economic development. In recent years, with the implementation of the Western Development Strategy, Tibet's economy has achieved rapid development, and the continuous increase of investment in transportation infrastructure has also greatly promoted the development of Tibet's transportation industry. The analysis of the current situation and relationship between the transportation industry and economic development in Tibet will help to find out the problems existing in the development of the transportation industry in Tibet at the present stage, so that the transportation industry can better play its role in promoting economic development.

Domestic scholars' studies on the relationship between transportation industry and economic development in the Tibet Autonomous Region mainly include the following two types. The first is qualitative analysis. Yang et al. (2005) believed that the construction of Qinghai-Tibet Railway was conducive to resource development, tourism development and industrial structure adjustment in Tibet, which will promote the economic growth of Tibet. Tian et al. (2013) discussed the construction measures of roads, railways and aviation in Tibet, and put forward the direction of building an integrated transportation infrastructure system that was suitable for Tibet's economic development. Luo (2016) believed that the development of transportation in Tibet promoted the development of its characteristic industries and the change of industrial structure, and significantly improved the investability of Tibet. The second is quantitative analysis method. Pan (2005) investigated the relationship between the development of transportation and GDP in Tibet and believed that the transportation industry had a great promoting effect on the economic growth, especially with a large correlation coefficient with the secondary and tertiary industries. Zong et al. (2013) used the CobbDouglas production function to prove the correlation between transportation investment and economic development in Tibet, and obtained the multiplier of transportation investment. Through correlation analysis and elasticity analysis between transportation and economic development, they concluded that the construction of transportation infrastructure was highly positively correlated with the economic development in Tibet. Wang et al. (2014) discussed the effect of QinghaiTibet Railway on the growth of economic aggregate in the counties and cities along the railway by using DID. The results showed that the Qinghai-Tibet Railway increased the per capita GDP of the counties and cities along the railway by more than $20 \%$. Li et al. (2016) analyzed the contribution of Qinghai-Tibet Railway to the GDP of Qinghai and Tibet through the Gray Forecast Model and with and without comparison method, and argued that the annual contribution rate of the registration of QinghaiTibet Railway to the total regional output of Tibet reached $8.1 \%$.

In general, most of the studies focus on the overall analysis of the relationship between the transportation industry and economic development to estimate the overall effect of the development of the transportation industry. There is a lack of quantifying the development

\footnotetext{
a* Corresponding author: 18241128@bjtu.edu.cn

b18241123@bjtu.edu.cn, ${ }^{c} 18241026 @$ bjtu.edu.cn
} 
of transportation industry into different indicators to discuss its relationship with economic development. Therefore, this paper will start from different indicators to measure the development of transportation industry and analyze its relationship with economic growth.

\subsection{Development status of transportation industry}

\subsubsection{The transportation infrastructure}

Since the economic reform and opening up, the transportation industry in Tibet has developed vigorously. At present, a relatively complete transportation system has been formed, including roads, railways, aviation and pipelines.

\subsubsection{Highway development situation}

Highway transportation is the main mode of transportation in Tibet. At present, a road network has been formed in Tibet, with Lhasa as the center and the Qinghai-Tibet Highway, the Xin-Tibet Highway, the Sichuan-Tibet Highway, the Yunnan-Tibet Highway, and the ChinaNepal Highway as the backbone. By 2017, the mileage of highways in Tibet Autonomous Region has reached 89343 $\mathrm{km}$, including 6 national highways, 12 district roads, 40 county roads, 327 township roads and 72 special roads. The main national highways in Tibet are shown in the table below:

Table1. Summary of Important National Roads in Tibet Autonomous Region

\begin{tabular}{|c|c|c|c|}
\hline $\begin{array}{c}\text { Name of } \\
\text { Highway }\end{array}$ & $\begin{array}{c}\text { Starting and } \\
\text { ending points }\end{array}$ & $\begin{array}{c}\text { Opening } \\
\text { time }\end{array}$ & Scale(km) \\
\hline $\begin{array}{c}\text { Qinghai- } \\
\text { Tibet } \\
\text { Highway }\end{array}$ & $\begin{array}{c}\text { Xining City - } \\
\text { Lhasa City }\end{array}$ & 1954 & 1937 \\
\hline $\begin{array}{c}\text { Xinjiang- } \\
\text { Tibet } \\
\text { Highway }\end{array}$ & Kashi - Xigaze & 1957 & 2269 \\
\hline $\begin{array}{c}\text { Sichuan- } \\
\text { Tibet } \\
\text { Highway }\end{array}$ & Chengdu - Lhasa & $\begin{array}{l}1954 \text { (North) } \\
1969 \text { (Full } \\
\text { line) }\end{array}$ & 2412 (North) \\
\hline $\begin{array}{c}\text { Yunnan- } \\
\text { Tibet } \\
\text { Highway }\end{array}$ & Kunming - Lhasa & 1976 & 1930 \\
\hline $\begin{array}{c}\text { Sino- } \\
\text { Nepalese } \\
\text { Highway }\end{array}$ & Kathmandu & 1965 & 943 \\
\hline
\end{tabular}

\subsubsection{Railway development situation}

Since the Qinghai-Tibet Railway was completed and opened to traffic, the snow-covered plateau has become the focus of world attention. Increasingly convenient transportation has made Tibet more accessible and less mysterious. Railway transportation has become an important mode of transportation in the Tibet Autonomous Region, adding a new booster to the economic and social development of Tibet. In the long run, the Tibet Autonomous Region will form five railway lines into
Tibet, namely, Qinghai Tibet railway, Xinzang railway, Sichuan Tibet railway, Yunnan Tibet railway and Gansu Tibet railway, which eventually develop into a plateau railway layout of "one vertical and one horizontal". The main railways in Tibet are shown in the table below:

Table2. tant National Roads in Tibet Autonomous Region

\begin{tabular}{|c|c|c|c|}
\hline $\begin{array}{l}\text { Name of } \\
\text { Highway }\end{array}$ & $\begin{array}{c}\text { Line } \\
\text { length } \\
(\mathbf{k m})\end{array}$ & $\begin{array}{c}\text { Total } \\
\text { investmen } \\
\text { t amount } \\
\text { (RMB) } \\
\end{array}$ & Road conditions \\
\hline $\begin{array}{l}\text { Qinghai- } \\
\text { Tibet } \\
\text { Highway }\end{array}$ & 1956 & 33 billion & Opened to traffic in 2006 \\
\hline $\begin{array}{l}\text { Xinjiang- } \\
\text { Tibet } \\
\text { Highway }\end{array}$ & 2010 & 96 billion & $\begin{array}{l}\text { In the planning survey } \\
\text { phase }\end{array}$ \\
\hline $\begin{array}{l}\text { Sichuan- } \\
\text { Tibet } \\
\text { Highway }\end{array}$ & 1629 & 270 billion & $\begin{array}{l}\text { Chengkang and Larin } \\
\text { (scheduled for 2026) }\end{array}$ \\
\hline $\begin{array}{l}\text { Yunnan- } \\
\text { Tibet } \\
\text { Highway }\end{array}$ & 1573 & & $\begin{array}{c}\text { Kunming Railway } \\
\text { (completed) } \\
\text { Dali Railway } \\
\text { (opened to traffic in 2009) } \\
\text { Lixiang Railway } \\
\text { (under construction) } \\
\text { Xianglin Railway } \\
\text { (under construction) } \\
\text { Larin Railway } \\
\text { (under construction) } \\
\end{array}$ \\
\hline $\begin{array}{c}\text { Gansu- } \\
\text { Tibet } \\
\text { Highway }\end{array}$ & 2126 & $\begin{array}{l}37.627 \\
\text { billion }\end{array}$ & $\begin{array}{c}\text { In the early stage of survey } \\
\text { and selection }\end{array}$ \\
\hline
\end{tabular}

\subsubsection{Transportation scale}

\subsubsection{Passenger and freight volume}

From the figure 1, we can see that the freight volume of Tibet has been increasing year by year from 2004 to 2018 . It increased from 2.46 million tons in 2004 to 24.33 million tons in 2018, an increase of nearly 10 times, with an average annual growth rate of $17.78 \%$. In addition to large fluctuations in 2007 and 2013, passenger volume in Tibet has also basically maintained an upward trend in recent years. It increased from 2.56 million in 2014 to 13.99 million in 2018 , an increase of nearly five times, with an average annual growth rate of $12.90 \%$.

On the one hand, the steady increase of passenger and freight volume is closely related to the gradual improvement of Tibet's transportation infrastructure and the improvement of its transportation capacity. On the other hand, it also shows that Tibet has increasingly close ties with the outside world, increasing the flow of goods and materials between Tibet and other regions. From 2007 to 2008 , both passenger and freight volume increased significantly. This benefited from the opening of the Qinghai-Tibet railway, which became a rapidly developing mode of transportation, solved the bottleneck problem of transportation in the Tibet Autonomous Region at that time, and thus led to the increase of passenger and freight volume. The large fluctuation of passenger volume from 2008 to 2013 May be related to the adjustment of the statistical caliber of passenger volume data in China during this period. 


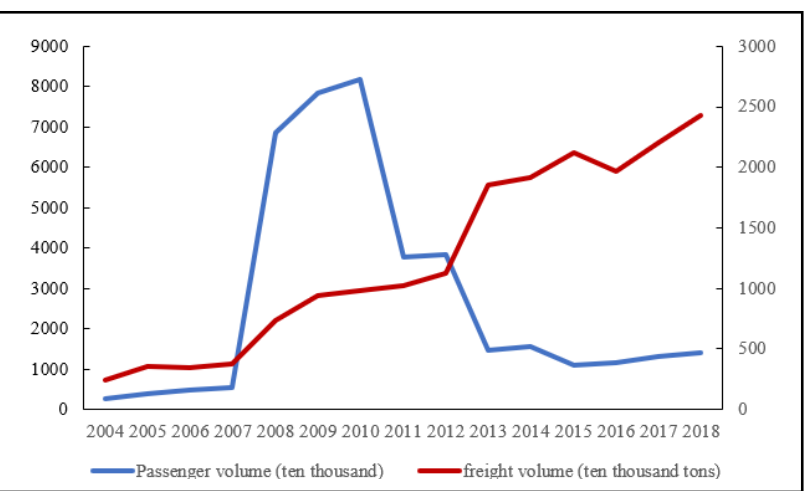

Figure 1 Passenger and freight volume in Tibet Autonomous Region from 2004 to 2018

\subsubsection{Passenger and Freight Turnover Volume}

From the change of passenger and freight turnover, they both have generally maintained an increasing trend. Among them, passenger turnover increased from 1.48 billion person-kilometers in 2004 to 4.683 billion personkilometers in 2018, a threefold increase with an average annual growth rate of $9.27 \%$. The freight turnover increased from 2.31 billion ton-km in 2004 to 15.06 billion ton- $\mathrm{km}$ in 2018, a six-fold increase with an average annual growth rate of $15.48 \%$, far surpassing the growth rate of passenger turnover.

The growth rate of freight turnover was basically the same as that of passenger turnover in 2012, but after 2012, the growth rate of freight turnover increased significantly, gradually widening the gap between freight turnover and passenger turnover. On the one hand, this was because Tibet had gradually formed a diversified transportation network linked by the Qinghai-Tibet Railway, which had become one of the important international channels in western China. It can directly connect with South Asia and complete the turnover of international freight transportation. On the other hand, the strategy of jointly building the "Silk Road Economic Belt" proposed by the President of China in 2013 also provided new opportunities for Tibet's economic development to the outside world and promoted the international trade of Tibet. Therefore, the average freight distance had a rapid growth, resulting in a substantial increase in the turnover of goods.

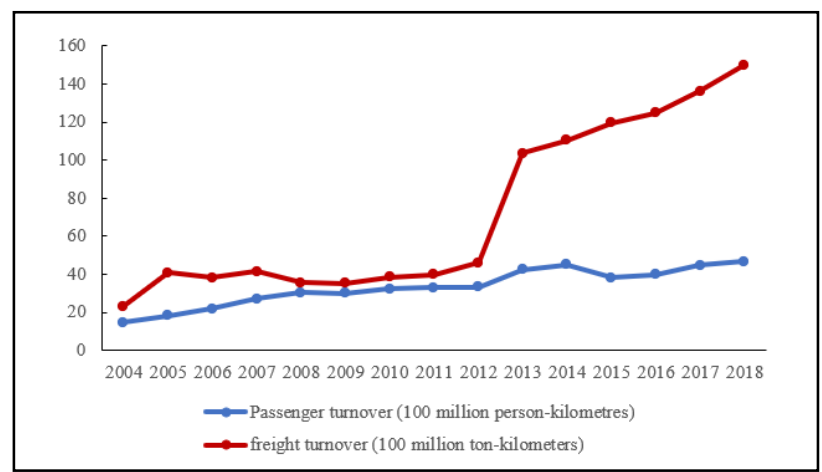

Figure 2 Passenger and freight turnover in Tibet Autonomous Region from 2004 to 2018

\subsubsection{Summary}

Through the above analysis, it can be found that with the continuous adjustment of national policies to Tibet and the gradual increase of support, the construction of transportation infrastructure in Tibet is becoming more and more perfect, the construction process of threedimensional transportation system is accelerating, and the scale of transportation also has a rapid growth. However, compared with the well-connected transportation network system of inland provinces and cities, Tibet is still relatively short of external channels. The railway transportation service is still concentrated in the economically developed areas of Tibet and the coverage rate is still not very high.

\subsection{Current situation of regional economic development}

\subsubsection{The overall situation of the economy in Tibet}

Along with the peaceful liberation of Tibet, the adjustment of the social system, and the convening of the Sixth Forum on Work in Tibet by the Central Committee of the People's Republic of China, all these have promoted the development of the productive forces and social progress in Tibet, and realized the leapfrog development of the Tibetan economy. Both GDP and per capita GDP have been greatly improved, gradually enhancing Tibet's economic power. From figure3, Tibet's GDP increased from 22.03 billion yuan in 2004 to 147.763 billion yuan in 2018 , an increase of nearly seven times, with an average annual growth rate of $15.77 \%$. The per capita GDP increased from 8,000 RMB in 2004 to 43,000 RMB in 2018, a five-fold increase, with an average annual growth rate of $13.81 \%$, which showed a linear growth trend from 2011 to 2018 .

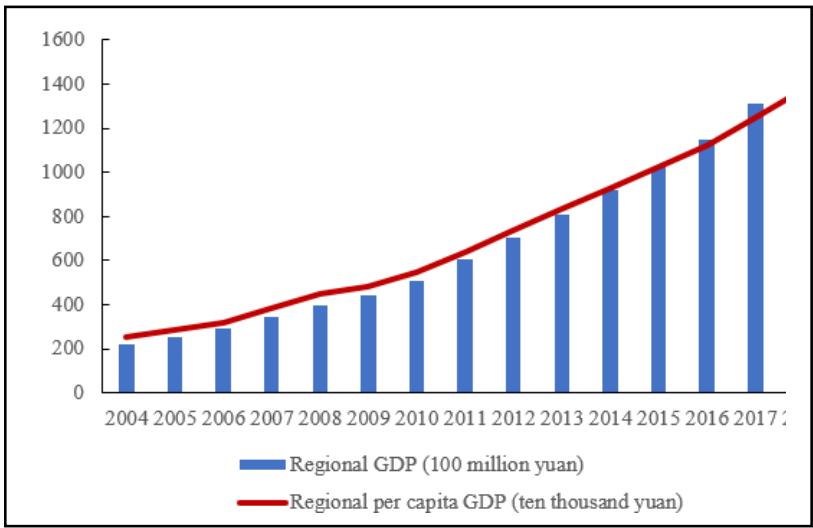

Figure 3 GDP and per capita GDP in Tibet Autonomous Region from 2004 to 2018

\subsubsection{Economic and industrial structure of Tibet}

From 2004 to 2018, the proportion of the primary industry in Tibet decreased by $11.3 \%$, the proportion of the secondary industry increased by about $18.6 \%$ compared with the lowest year in 2004 (23.9\%), and the proportion of the tertiary industry decreased by $7.3 \%$. In 2004 , the output value structure of the three industries in Tibet 
presented a "J" shape, that is, the "three, two and one" structure (the output value of the tertiary industry is greater than the output value of the secondary industry, and the output value of the secondary industry is greater than the output value of the primary industry), which has been maintained since then. According to the Petty-Clark Principle, with the development of economy, the change trend of the added value of the three industries in the GDP structure is that the proportion of the primary industry keeps declining while the proportion of the secondary and tertiary industries keeps rising. According to this theory, the industrial output value structure of Tibet is tending to rationalize at present.

\section{Empirical Analysis}

\subsection{Grey relation analysis}

\subsubsection{Model selection and description of data and indicators}

This part studies the relationship between the transportation industry and economic growth in Tibet Autonomous Region from the perspective of transportation scale. Among them, passenger volume, passenger turnover, freight volume and freight turnover are selected as the indicators of transportation development, namely the sequence of influencing factors. The GDP of Tibet Autonomous Region is selected as the economic growth index, namely the target factor sequence. The data period was from 2004 to 2018 and came from the statistical yearbook of the Tibet Autonomous Region for each year.

The following attempts to use the grey relation analysis

(GRA) method to analyze the impact of various factors of the transportation scale on the economy, hoping to find out those factors that have a greater impact on economic growth and play a driving role in economic growth.

\subsubsection{Analysis on the relationship between the total scale of transportation and economic growth}

According to Table 3, there is a high correlation degree between each index of transportation industry and economic growth in Tibet Autonomous Region from 2004 to 2018 , with an average correlation degree of about 0.686 . The correlation degree between each index of transportation industry and GDP is freight volume, freight turnover, passenger turnover and passenger volume from big to small. This shows that freight transportation has a greater impact on the economic growth of Tibet Autonomous Region. In terms of economic growth stage, the correlation degree between other transportation indicators and GDP except passenger volume shows a trend of increasing at first and then decreasing, and the correlation value of freight volume and freight turnover is much higher than passenger volume. This shows that the development of cargo transportation plays a greater role in the economic development of Tibet Autonomous Region than passenger transportation. This is related to the fact that Tibet Autonomous Region imported a large number of goods and services from the mainland in order to meet the needs of economic construction, production development and people's life at the early stage of economic development. However, with the improvement of economic development level, the constant adjustment of industrial structure and the improvement of people's living standards, the flow of personnel began to increase and the tourism industry continued to develop. So the demand for passenger transportation continued to increase and the impact of passenger transportation on economic development gradually increased. From 2010 to 2018, the correlation between passenger volume and GDP continued to rise.

Table3. Grey correlation degree between each index of total transportation scale and GDP

\begin{tabular}{|c|l|c|l|c|c|}
\hline $\begin{array}{c}\text { Period of } \\
\text { time }\end{array}$ & $\begin{array}{l}\mathbf{2 0 0 4 -} \\
\mathbf{2 0 0 6}\end{array}$ & $\begin{array}{c}\mathbf{2 0 0 7 -} \\
\mathbf{2 0 0 9}\end{array}$ & $\begin{array}{l}\mathbf{2 0 1 0 -} \\
\mathbf{2 0 1 2}\end{array}$ & $\begin{array}{c}\mathbf{2 0 1 3 -} \\
\mathbf{2 0 1 5}\end{array}$ & $\begin{array}{c}\mathbf{2 0 1 6 -} \\
\mathbf{2 0 1 8}\end{array}$ \\
\hline $\begin{array}{c}\text { passenger } \\
\text { volume }\end{array}$ & 0.5538 & 0.4885 & 0.4488 & 0.4719 & 0.5596 \\
\hline $\begin{array}{c}\text { freight } \\
\text { volume }\end{array}$ & 0.6113 & 0.7243 & 0.8504 & 0.8446 & 0.7596 \\
\hline $\begin{array}{c}\text { passenger } \\
\text { turnover }\end{array}$ & 0.8066 & 0.9464 & 0.8121 & 0.5922 & 0.4824 \\
\hline $\begin{array}{c}\text { freight } \\
\text { turnover }\end{array}$ & 0.563 & 0.7889 & 0.864 & 0.8826 & 0.6638 \\
\hline
\end{tabular}

\subsubsection{Correlation analysis between railway and highway transportation modes and economic development}

It can be seen from Table 4: First of all, on the whole, railway transportation has a greater impact on economic development in the transportation system of Tibet Autonomous Region, and the correlation degree between railway transportation indicators and GDP is about 0.867 on average, exceeding that of highways. This shows that the development of railway transportation plays a more prominent role in supporting the economic development of Tibet Autonomous Region. Secondly, from the perspective of the two modes of transportation and the structure of passenger and freight transportation, the order of correlation degree between railway transportation indexes and GDP is passenger turnover $>$ freight turnover $>$ passenger volume $>$ freight volume, and the order of correlation degree between highway transportation indexes and GDP is freight volume $>$ freight turnover $>$ passenger turnover $>$ passenger volume. That is to say, the turnover of passenger and freight transportation in railway transportation is closely related to GDP, and freight transportation in highway transportation plays a greater role in economic development.

Table4. Grey correlation degree between each index of two modes of transportation and GDP

\begin{tabular}{|l|c|c|c|c|}
\hline & $\begin{array}{c}\text { passenger } \\
\text { volume }\end{array}$ & $\begin{array}{c}\text { Passenger } \\
\text { turnover }\end{array}$ & $\begin{array}{c}\text { Freight } \\
\text { volume }\end{array}$ & $\begin{array}{c}\text { Freight } \\
\text { turnover }\end{array}$ \\
\hline railway & 0.8832 & 0.9079 & 0.7747 & 0.902 \\
\hline highway & 0.5517 & 0.7703 & 0.8971 & 0.8615 \\
\hline
\end{tabular}




\subsection{Coordination analysis of transportation industry and economic growth}

This section analyzes the coordination between transportation industry and its economic growth, finds out the problems and puts forward suggestions on this basis, which is of guiding significance for the future development of transportation industry in Tibet Autonomous Region.

\subsubsection{Transport elasticity coefficient}

Elasticity coefficient is the ratio of the growth rate of two interrelated economic indicators in a certain period. It measures the dependence of the growth rate of one economic variable on the growth rate of another economic variable. It is usually used to compare the coordinated development of two economic variables in a region. When examining the coordination of transportation industry and economic growth, we can preliminarily judge whether the development of the two is coordinated or not by calculating the transport elasticity coefficient. Suppose $e_{i}$ is the transport elasticity coefficient of the $i^{\text {th }}$ period, $\mathrm{x}_{\mathrm{i}}$ is the growth rate of transportation index (passenger volume, freight volume, passenger turnover or freight turnover) in the $i^{\text {th }}$ period, $\mathrm{y}_{\mathrm{i}}$ is the growth rate of economic indicators in the $i^{\text {th }}$ period, then $\mathrm{e}_{\mathrm{i}}=\frac{\mathrm{x}_{\mathrm{i}}}{\mathrm{y}_{\mathrm{i}}}$.

\subsubsection{Results analysis}

From the previous development introduction, we can also know that the development speed of the transportation industry in Tibet Autonomous Region from 2013 to 2018 was basically equal to the speed of economic growth. Then we will analyze the results in Table 5 in detail to explore the coordination between the transportation industry and economic growth.

In terms of total volume, except for the small elastic coefficient of passenger turnover, other elastic coefficients are all around 1, which shows that the development of transportation industry in Tibet Autonomous Region is basically compatible with economic growth. This shows that China's investment in the Tibet Autonomous Region has achieved remarkable results, the transportation capacity is gradually improving and the degree of satisfaction with economic needs is gradually improving.

Comparing and analyzing the interior of transportation system, it is found that cargo transportation is more developed than passenger transportation, which is closely related to the closer trade between Tibet Autonomous Region and other regions under the background of "the belt and road", and the substantial increase of cargo transportation. At the same time, it also shows that passenger transportation still has a certain growth space relative to economic growth, and the promotion of economic growth to passenger transportation needs to be strengthened.

From the point of transportation mode, the transportation elasticity coefficient of railway related indexes is greater than 1 , while that of highway related indexes is less than 1 except freight volume, and the elasticity coefficient of railway transportation indexes is greater than that of highway. This fully shows that the speed of railway construction has far exceeded the speed of economic growth in Tibet Autonomous Region in recent years, and the speed of railway construction is obviously faster than that of highway construction. On the one hand, this is due to the implementation of the western development strategy, and the state has continuously increased its investment in the transportation infrastructure of the Tibet Autonomous Region, especially the construction of the Qinghai-Tibet Railway, which has solved the bottleneck problem of transportation in the Tibet Autonomous Region and gradually improved its transportation capacity; On the other hand, due to the restriction of natural conditions, the traffic capacity of highway transportation is poor and highway construction has encountered many difficulties.

Table5. Transport Elasticity Coefficient of Tibet Autonomous Region from 2013 to 2018

\begin{tabular}{|c|c|c|c|c|}
\hline & $\begin{array}{c}\text { Passenger } \\
\text { volume }\end{array}$ & $\begin{array}{c}\text { Freight } \\
\text { volume }\end{array}$ & $\begin{array}{c}\text { Passenger } \\
\text { turnover }\end{array}$ & $\begin{array}{c}\text { Freight } \\
\text { turnover }\end{array}$ \\
\hline railway & 1.4057 & 2.3783 & 1.0487 & 1.9473 \\
\hline highway & 0.5097 & 1.1975 & 0.2385 & 0.7003 \\
\hline $\begin{array}{c}\text { total } \\
\text { capacity }\end{array}$ & 0.8852 & 1.2227 & 0.5877 & 0.9819 \\
\hline
\end{tabular}

\subsubsection{Summary}

This chapter mainly makes an empirical analysis of the relationship between the transportation scale and economic growth in Tibet Autonomous Region. Firstly, the paper analyzes the factors of transportation scale that influence economic development by using the grey correlation theory, and finds out the factors of transportation that have greater influence on economic growth. Then, it further calculates the transportation elasticity coefficient, and makes a preliminary discussion on the coordination between the two development in Tibet Autonomous Region. The empirical results draw the following main conclusions:

First, the grey correlation analysis shows that there is a high correlation degree between the transportation industry and economic growth in Tibet Autonomous Region in the 15 years from 2004 to 2018, with an average correlation degree of about 0.686 , but the correlation degree between the two shows a downward trend; From the structural point of view, cargo transportation plays a greater role in the economic growth of Tibet Autonomous Region than passenger transportation, and the development of railway transportation plays a more prominent supporting role in the economic development of Tibet Autonomous Region. The railway has more advantages in freight turnover and passenger turnover, while the highway has a greater impact on economic development in terms of freight turnover and freight volume.

Secondly, the results of elastic analysis show that the transportation industry and economic growth in Tibet Autonomous Region are in a coordinated state as a whole, 
and the transportation supply can basically meet the transportation demand. Comparing and analyzing the interior of transportation system, it is found that cargo transportation is relatively developed and passenger transportation supply needs to be increased. From the perspective of railway and highway, the driving effect of economic growth on railway transportation is far greater than that of highway transportation, and the speed of railway construction is far faster than that of economic growth, while highway construction still can not meet the needs of social and economic development.

\section{Conclusions and suggestions}

To sum up, there is a close relationship between the transportation industry and economic growth in Tibet Autonomous Region. In recent years, the transportation development speed of Tibet Autonomous Region is fast, which is generally suitable for its economic growth speed. In order to make the transportation industry play a better role in promoting and guiding the economy of Tibet Autonomous Region and realize the coordinated relationship between transportation and regional economic development, we put forward the following suggestions:

Continue to intensify the construction of transportation infrastructure in the Tibet Autonomous Region. At present, there are still some problems in Tibet Autonomous Region, such as insufficient total amount and low density of transportation network, low highway grade. Therefore, in order to better meet the needs of Tibet Autonomous Region's sustained and rapid economic development, we must expand the scale of transportation network and improve the coverage of highway and railway.

Improve the transportation quality of Tibet Autonomous Region and the comprehensive threedimensional transportation system. We should accelerate the development of high-quality transportation in Tibet Autonomous Region, focus on building a comprehensive three-dimensional transportation network, build a large open channel for South Asia, accelerate the construction of access roads to Tibet, and build Sichuan-Tibet Railway with high starting point, high standard and high quality.

Open up financing channels. In view of the nature of large investment and public goods in transportation infrastructure, the local government can also raise funds through other channels to improve the transportation conditions in the area when the central government's investment is limited.

\section{References}

1. B. Q. Yan, J. S. Zhang, "The Related Research of Transportation and Economic Development in China," Advanced Materials Research, vol. 403-408,pp.15601563,2011 , doi:10.4028/www.scientific.net/AMR.403-408.1560

2. B Yang, M.Q Pan, "Research on the Qinghai Tibet railway to promote the economic development of Tibet," Exploration of economic problems, vol. 4, pp. 71-73, April 2005
3. R.Y. Tian, J.H. Wang, and L.S. Li, "Analysis on the construction of comprehensive transportation system in Tibet," Tibet Science and technology. vol.6, pp.6264, June 2013, doi:CNKI : SUN:XZKJ.0.2013-06027.

4. W.D. Li, Y. Zhang, "The impact of Qinghai Tibet railway operation on Tibet's economic development," China Railway, vol. 5, pp. 12-16, May 2016, doi: 10.19549/j.issn.1001-683x.2016.05.003.

5. G. Zong, J. Li, “An Empirical Study on the positive interaction between transportation and economy in Tibet," China Tibetology. vol. 3, pp. 113-120, March 2013, doi: CNKI : SUN:CTRC.0.2013-03-015.

6. J.Y. Pan, “An Empirical Study of transportation and economic development in Tibet," Guizhou ethnic studies, vol. 6, pp. 97-105, June 2005, doi: CNKI : SUN:GZNY.0.2005-06-015.

7. J.B. Pan, "Research on the relationship between transportation and economic development in Tibet," Guizhou Ethnic Studies, vol. 3, pp. 117-121, March 2009, doi: CNKI : SUN:GZNY.0.2009-03-025.

8. Y. Wang, B.Z. Wu, "Can infrastructure construction promote the development of local economy? -Taking the Qinghai Tibet Railway as an example,"Acta economica Sinica, vol. 1, pp. 55-80, January 2014, doi: 10.16513/j.cnki.cje.2014.01.001.

9. P. Zhang, S.P. Cui, "An analysis of the relationship between Tibet's economic development and transportation,"Western China Science and technology, vol. 25, pp. 5-6 + 18, September 2009, doi:CNKI : SUN:XBKJ.0.2009-25-003.

10. G. Chen, J. Zhang, "The coordinated research of transportation and economic development in China," IEEE, 2011, doi :10.1109/ICMT.2011.6002964

11. T.Y. Ma, "Research on the relationship between transportation and economic development in Tibet," modern economic information. vol. 5, pp. $193+195$, 2020, doi:CNKI : SUN:XDJZ.0.2020-05-112.

12. Y. Li, "Evaluation and analysis of the quality of economic growth in Tibet (2012-2018)," Journal of Tibet University for Nationalities (PHILOSOPHY AND SOCIAL SCIENCES EDITION), vol. 6, pp. 140-145, June 2019, doi:CNKI : SUN:XZMZ.0.201906-026.

13. Y. Liu, "One of the "one belt, one road" promotion of transportation infrastructure development in Tibet's regional economic growth," Logistics technology, vol. 11, pp. 106-108, November 2017, doi:10.13714/j.cnki.1002-3100.2017.11.027.

14. X. Zhang, X. Wang, G. H. Wang, F. C. Sun,. “A comprehensive framework of transportation infrastructure promoting economic growth," economic research, vol. 1, pp. 50-64, January 2018, doi:CNKI : SUN: JJYJ.0.2018-01-005.

15. L Luo, "Research on the relationship between transportation and economic development in Tibet," economic and trade practice, vol. 24, pp. 134, 2016, doi:CNKI : SUN:JMSA.0.2016-24-106. 